\title{
REINCIDÊNCIA CRIMINAL: ESTUDO DE ALGUMAS CARACTERÍSTICAS INDIVIDUAIS
}

\author{
José Maria Marlet \\ Professor Associado do Departamento de Medicina Forense da \\ Faculdade de Direito.da Universidade de São Paulo. \\ Issao Kameyama \\ Professor de Medicina Legal da Faculdade de Direito da Pontifícia \\ Universidade Católica e da Academia de Polícia de São Paulo.
}

\begin{abstract}
Resumo: Os autores estudam $5 \mathrm{mil}$ criminosos reincidentes quanto à cor da pele, a idade ao cometerem o primeiro delito, ao número e tipo dos ilícitos penais cometidos e ao intervalo de tempo transcorrido entre as reincidências. Concluem ser a reincidência criminal menos freqüente do que se pensa $(13,1 \%$ com uma reincidência, $4,8 \%$ com duas e $2,8 \%$ com três). Que para cada grupo de 100 mil pessoas da mesma cor, os pardos são os que mais reincidem $(39,2)$, seguidos dos pretos $(31,0)$, dos brancos $(8,0)$ e dos amarelos $(4,9)$. Que a reincidência é fundamentalmente problema que atinge $o$ adulto jovem. Que as reincidências são mais freqüentes aos crimes contra a pessoa e contra o patrimônio. E que os intervalos de tempo entre as reincidências aumentam na medida em que aumenta o seu número.
\end{abstract}

Resumen: Los autores estudiam $5 \mathrm{mil}$ criminales reincidentes en lo que se refere al color de la piel, a la edad al cometer el primer delito, al número y tipo de los ilícitos penales y a los intervalos de tiempo entre los crimenes. Concluen que la reincidencia criminal es menos frequente de lo que se imagina (13,1\% con una reincidencia, $4,8 \%$ con dos y $2,8 \%$ con tres). Que para cada grupo de 100 mil personas del mismo color de piel, los mulatos son los que más reincidem $(39,2)$, seguidos por los negros $(31,0)$, los brancos $(8,0)$ y los amarillos $(4,9)$. Que la reincidencia es problema fundamentalmente del adulto joven. Que las reincidencias son más frequentes en los crimines contra la persona y contra el patrimonio. $Y$ que los intervalos de tiempo entre las reincidencias aumentan a medida que aumenta su numero.

Unitermos: Reincidência Criminal, Criminosos à cor da pele; Crimes quanto à pessoa; Crimes quanto ao patrimônio.

$E$ de longa data que a reincidência criminal preocupa os estudiosos da problemática criminológica.

"Tudo deve ser feito para a cura do delinqüente. Mas, mesmo quando o tratamento tenha sido o mais desvelado, há sempre a possibilidade de uma recaída e aparece, assim, a reincidência", como nos ensina o professor Veiga de Carvalho. (5) 
O conceito de reincidência é jurídico-formal, pois baseia-se na existência de condenação anterior em prazo fixado em lei. Lopez-Rey afirma ${ }^{(2)}$, acompanhado por numerosos criminalistas, que a reincidência não deve constituir-se na base de períodos e condenações, para os quais não achei nunca explicações satisfatórias em eminentes penalistas e juízes. A reincidência deve ser pessoalmente estabelecida e não na forma linear em que é feita e muito menos baseá-la na periculosidade, coisa que a maioria das vezes reflete uma consciência de classes dominantes, tanto em países de direita quanto de esquerda. Para estabelecê-la deve levar em conta a idade...."e outras variáveis individuais".

É necessário, pois, estudar as características subjetivas dos reincidentes, visando ao prognóstico entende-se normalmente em criminologia uma afirmação sobre a futura conduta de um indivíduo ou grupo, referindo-se à observação da lei, continuando, "o ponto essencial do prognóstico encontra-se no terreno das decisões judiciais".

A Lei 7.210/84 (Lei das Execuções Penais) enfatiza a necessidade da avaliação do prognóstico criminológico, tanto para fins de classificação e triagem, dos condenados, quanto para fins de escolha do regime de cumprimento da pena, bem como para concessão de benefícios. Sá ${ }^{(4)}$ lembra ser importante, nesse sentido, conhecer quais os fatores que favorecem a reincidência e que grupos de presos podem ser considerados de maior risco de reincidência".

Dos três métodos utilizados para o prognóstico criminológico - o intuitivo, o clínico e o estatístico - preferimos o último, pois o primeiro carece dos necessários conhecimentos científicos e o segundo está eivado pelos subjetivismos do avaliador.

Para isso, selecionamos aleatoriamente uma amostra de 5 mil prontuários criminais cadastrados pela Secretaria Estadual dos Negócios da Segurança Pública do Estado de São Paulo e arquivados no Sistema de Computadores da PRODESP Processamento de Dados do Estado de São Paulo.

Limitamos nosso estudo às reincidências em ilícitos penais que se refiram aos dispositivos do Código Penal, excluindo-se os crimes tipificados em outras leis como, por exemplo, a Lei $n^{2} 6.368 / 76$, que trata do uso e comércio de substâncias toxidependentes, ou a Lei 7.170/83, que atenta para os problemas da segurança nacional, ou, ainda o Decreto Lei $\mathrm{n}^{\varrho} 3.688 / 41$, que se ocupa das contravenções penais.

O critério para a escolha daqueles ilícitos penais decorre das contradições na conceituação legal de reincidência. Senão, vejamos. O Código Penal (art.46) dispõe: "verifica-se a reincidência, quando o agente comete novo crime, depois de transitada em juízo a sentença que, no país ou no estrangeiro, o tenha condenado por crime anterior".

O artigo $7^{0} \mathrm{da}$ lei das Contravençōes Penais afirma: "verifica-se a reincidência quando o agente pratica uma contravenção depois de passar em julgado a sentença que o tenha condenado no Brasil, ou no estrangeiro, por qualquer crime ou, no Brasil, por motivo de contravenção".

Devemos lembrar que, na nossa legislação penal vigente, o conceito de reincidência exige que o novo crime seja praticado antes dos cinco anos, contados a partir do cumprimento ou extinção da pena (Parágrafo único do art. 46 do Código Penal). 
Estudamos a cor da pele dos criminosos, agrupando-os, de acordo com a rotina do trabalho policial, em brancos $(\mathrm{Br})$, pretos $(\mathrm{Pr})$, pardos $(\mathrm{Pa})$ e amarelos (Am); sua idade ao cometer novos crimes, agrupando-os em classes de intervalo igual a cinco anos exceto o primeiro cuja ocorrência, por imposição legal, deve verificar-se a partir de 18 anos; os tipos de delitos cometidos, agrupados segundo os títulos do Código Penal e os intervalos de tempo transcorridos entre as reincidências, juntados em classe de intervalo de um ano.

Deixamos de nos preocupar com o sexo dos criminosos reincidentes, pois Rodello e col ${ }^{(3)}$, trabalhando com amostra da mesma população, mostraram que a diferenciação por sexo dos criminosos reincidentes é irrelevante, pois ambos os sexos reincidem com as mesmas freqüências.

Deixamos, igualmente, de nos preocupar com a classificação profissional dos criminosos por se tratar de dado carente de credibilidade, visto que cabe ao próprio delinqüente declinar sua profissão no momento da abertura do inquérito policial.

Empregamos o teste não paramétrico para avaliar a significância estatística das diferenças entre as modalidades das diversas variáveis estudadas, estabelecendo o nível de rejeição em 5\%. Marcamos com asterisco os valores estatisticamente significantes.

Este trabalho foi realizado na Escola de Polícia Civil de São Paulo, graças ao convênio existente entre a nossa Faculdade e a Secretaria de Segurança Pública.

\section{Discussão}

A tabela 01 mostra que, nos 5 mil prontuários criminais examinados, 3.707 pertenciam a réus primários; 656 eram de delinqüentes que tinham cometido apenas uma reincidência, 239 tinham cometido duas reincidências, 138 três reincidências e 85, quatro. Dado o número reduzido de casos com mais de quatro reincidências (3,5\% do total), preferimos não incluí-los no estudo.

Esta tabela chama a atenção para o fato de serem as reincidências muito menos freqüentes do que se tem propalado habitualmente. Haja vista que com uma reincidência houve apenas $13,1 \%$, com duas, $4,8 \%$, com três, $2,8 \%$ e com quatro, $1,7 \%$.

Do exposto, podemos deduzir que a frequiência das reincidências é menor do que se supõe habitualmente, e que diminui na medida em que aumenta o respectivo número, independente da cor dos criminosos, de sua idade ao reincidir e do tipo de delito cometido.

Em relação à cor da pele dos criminosos, encontramos entre os delinqüentes reincidentes: 632 brancos, 12 amarelos, 174 pretos e 295 pardos (tabela 02). O teste de Kruskal-Wallis mostra (tabela 03) que as percentagens de reincidentes mantêmse constantes ao aumentar o número de reincidências, qualquer que seja a cor do criminoso $(H=0,09)$, mas que há diferença entre as cores $\left(H=14,12^{*}\right)$.

Aparentemente os brancos reincidem em número maior que os de outras cores, sendo irrisório o número de amarelos que reincidem. Isto é devido à heterogeneidade cromática da nossa população. Se calcularmos os coeficientes específicos de reincidência para cada cor, observaremos (tabela 04) que o número 
de reincidentes pardos é de 39,2 para cada grupo de 100 mil pessoas pardas; 31,0 reincidentes para o mesmo número de pessoas pretas; 8,0 de brancos e 4,9 de amarelos.

Estes coeficientes foram calculados baseados nos dados do recenseamento geral do Brasil de 1960, pois os feitos em 1970 e 1980 não incluíram o item cor. Isto se torna especialmente evidente nos gráficos das figuras 02 e 03 .

As tabelas 05 e 06 mostram as distribuições das idades dos criminosos ao reincidirem (figuras 04 e 05 ). o teste de Kruskal-Wallis mostra não haver diferença significante entre as proporções de reincidências $(H=1,45)$, mas sim entre as idades $\left(\mathrm{H}=47,08^{*}\right)$.

Não havendo diferença significante no comportamento etário ao aumentar o número de reincidências, calculamos as freqüências relativas acumuladas (tabela 06) que nos mostraram ser a reincidência problemas do adulto jovem, pois dois terços das reincidências ocorrem antes dos 30 anos de idade.

Na tabela 07 observamos que as reincidências criminais mais comuns são contra a pessoa (título I do Código Penal) e contra o patrimônio (título II do mesmo Código). Os outros ilícitos penais, por aparecerem em pequeno número, foram juntados num mesmo grupo. As percentagens de crimes contra a pessoa, contra o patrimônio e outros encontram-se na tabela 08 e estão representadas nos gráficos das figuras 06 e 07.

Novamente (tabela 08) não encontramos significância estatística entre as proporções de reincidências $(H=0,08)$, mas a encontramos entre os tipos de crime $\left(\mathrm{H}=9,84^{*}\right)$.

Como não achamos diferenças significantes nos diversos números de reincidência nos vários títulos, calculamos as médias aritméticas das percentagens de ocorrência das reincidências (tabela 08 ).

Aparentemente as reincidências contra o patrimônio $(34,6 \%)$ são mais freqüentes que as praticadas contra a pessoa (31,5\%), mas a diferença entre estas duas percentagens é estatisticamente não significante (qui-quadrado $=0,15$ ); logo, podemos afirmar que as reincidências contra a pessoa são tão freqüentes quanto as praticadas contra o patrimônio.

Os intervalos entre as reincidências, segundo a cor dos agentes, foram apresentados na tabela 09. O teste de Kruskal-Wallis, calculando com as médias aritméticas das durações dos intervalos de tempo entre as reincidências nos vários grupos dermocromáticos, mostra não haver diferença significante entre as cores da pele $(H=0,35)$.

Havendo diferenças significantes entre os intervalos de tempo, segundo o número de reincidências cometidas, $\left(\mathrm{H}=8,17^{*}\right)$, apresentamos as médias destes intervalos na tabela 11, assim como seus limites de confiança $95 \%$, o mesmo fazendo no gráfico da figura 09 .

Do exposto, podemos afirmar que os intervalos entre as reincidências são iguais para todos os grupos dermocromáticos e que as reincidências apresentam intervalos de tempo entre elas cada vez maiores, na medida em que aumenta o respectivo número. 
Observe-se que, sendo muito pequeno o número de reincidentes amarelos, em relação aos outros grupos dermocromáticos, os excluímos do estudo, pois não nos parece prudente estender à população as informações fornecidas pela amostra a seu respeito.

Os criminosos tendem a demorar (tabelas 12 e 13 e figura 10), em média, o mesmo tempo para reincidir, qualquer que seja a sua idade $(H=4,89)$ e que estes intervalos tendem a ficar cada vez mais longos, na medida em que cresce o número de reincidências $\left(H=20,71^{*}\right)$.

Em relação aos títulos do Código Penal em que as reincidências incidem (tabelas 14 e 15 e gráfico 11) só encontramos diferenças estatisticamente significantes $\left(H=8,89^{*}\right)$ entre os números de reincidências, pois os intervalos de tempo entre as reincidências nos crimes contra a pessoa são os mesmos que se encontram nas reincidências contra o patrimônio. •

\section{Conclusões}

Desta pesquisa podemos concluir:

$1-25,9 \%$ dos criminosos reincidem.

2 - Apenas $12,8 \%$ reincidem mais de uma vez.

3 Os criminosos de cor parda são os que reincidem com maior freqüência $(39,2 \%)$, seguidos de perto pelos de cor preta $(31,0 \%)$

4 - A máxima freqüência das reincidências ocorre na idade de 20 a 25 anos, sendo que mais de $60 \%$ das reincidências são praticadas por criminosos com menos de 30 anos de idade.

5 - A reincidência em crimes contra a pessoa $(31,5 \%)$ não difere da dos crimes contra o patrimônio $(34,6 \%)$.

60 intervalo entre as reincidências tende a aumentar na medida que aumenta o número das mesmas.

7 - A cor da pele dos criminosos não influi na magnitude dos intervalos entre as reincidências.

8 - O mesmo pode se afirmar em relação às idades dos criminosos ou entre os crimes contra a pessoa e contra o patrimônio. 
Tabela 01 : Criminosos segundo o número das reincidências cometidas.

\begin{tabular}{c|r|c}
\hline Reincidencias & Núnero & $\%$ \\
\hline 0 & 3.787 & 74,1 \\
1 & 656 & 13,1 \\
2 & 239 & 4,8 \\
3 & 139 & 2,8 \\
4 & 85 & 1,7 \\
5 & 47 & 8,9 \\
6 & 39 & 0,6 \\
7 & 25 & 9,5 \\
8 & 15 & 8,3 \\
9 & 18 & 0,2 \\
10 & 9 & 0,2 \\
110 & 39 & 0,8 \\
\hline Iotal & 5.800 & 1809,8 \\
\hline
\end{tabular}


Tabela 02 : Reincidências, segundo a cor da pele dos criminosos.

\begin{tabular}{l|r|r|r|r|r}
\hline \multirow{2}{*}{ Car } & \multicolumn{4}{|c|}{ Reincidencias } & \multirow{2}{*}{ Iotal } \\
\cline { 2 - 6 } & $1 \underline{a}$ & $2 \underline{a}$ & $3 \underline{a}$ & $4 a$ & \\
\hline Branca & 407 & 124 & 64 & 37 & 632 \\
Amarela & 19 & 1 & 1 & - & 12 \\
Preta & 86 & 45 & 28 & 15 & 174 \\
Parda & 151 & 68 & 44 & 32 & 295 \\
Ignorado & 2 & 1 & 1 & 1 & 5 \\
\hline Iotal & 6556 & 239 & 138 & 85 & 1118 \\
\hline
\end{tabular}

Tabela 03 : Percentagens de reincidências, segundo a cor da pele dos criminosos.

\begin{tabular}{|c|c|c|c|c|c|c|}
\hline \multirow{2}{*}{ Cor } & \multicolumn{4}{|c|}{ Reincidências } & \multirow{2}{*}{$x$} & \\
\hline & 1 & $2 \mathrm{a}$ & $3 a$ & $4 a$ & & \\
\hline Branca & 62,8 & 51,9 & 46,4 & 43,5 & 56,5 & \\
\hline Aarela & 1,5 & 0,4 & 0,7 & - & 1,1 & $H=14,12^{*}$ \\
\hline Preta & 13,1 & 18,8 & 20,3 & 17,6 & 15,6 & \\
\hline Parda & 27,8 & 28,5 & 31,9 & 37,6 & 26,4 & \\
\hline Ignorado & 0,3 & 0,4 & 8,7 & 1,2 & 8,4 & \\
\hline Iotal & 100,8 & 100,0 & 100,8 & 100,8 & 180,8 & \\
\hline
\end{tabular}


Tabela 04 : Coeficientes de reincidência por cor da pele dos criminosos, para grupos de 100.000 pessoas da mesma cor.

\begin{tabular}{l|c}
\hline Cor & Coef iciente \\
\hline Branca & 8,8 \\
Anarela & 4,9 \\
Preto & 31,8 \\
Pardo & 39,2 \\
\hline
\end{tabular}


Tabela 05 : Reincidências, segundo a idade dos criminosos ao cometê-las.

\begin{tabular}{|c|c|c|c|c|c|}
\hline \multirow{2}{*}{ Idade } & \multicolumn{4}{|c|}{ Reincidências } & \multirow{2}{*}{ lotal } \\
\hline & $1^{\underline{a}}$ & $2^{a}$ & 3 a & $4 \stackrel{a}{-}$ & \\
\hline $18-28$ & $\pi$ & 39 & 59 & 38 & 213 \\
\hline $20-25$ & 181 & 89 & 36 & 19 & 316 \\
\hline $25-38$ & 139 & 47 & 12 & 8 & 2065 \\
\hline $39-35$ & 94 & 26 & 16 & 10 & 146 \\
\hline $35-49$ & 69 & 22 & 6 & 5 & 102 \\
\hline $48-45$ & 41 & 13 & 5 & 2 & 61 \\
\hline $45-58$ & 27 & 5 & 3 & - & 35 \\
\hline $58-55$ & 12 & 2 & - & 2 & 16 \\
\hline $55-68$ & $?$ & 3 & - & - & 10 \\
\hline $68-65$ & 4 & 1 & - & - & 5 \\
\hline $65-78$ & 1 & - & - & - & 1 \\
\hline $79-75$ & - & - & - & - & - \\
\hline $75-89$ & 1 & - & - & - & 1 \\
\hline $88-85$ & - & - & - & - & - \\
\hline Ignorada & 3 & 1 & 1 & 1 & 6 \\
\hline lotal & 656 & 239 & 138 & 85 & 1118 \\
\hline
\end{tabular}


Tabela 06 : Percentagens de reincidências, segundo a idade dos criminosos ao cometê-las.

$$
\begin{aligned}
& \begin{array}{c|c|c|c|ccc|c}
\hline \multirow{2}{*}{\text { Idade }} & \multicolumn{4}{|c|}{\text { Reincidências }} & & \multirow{2}{*}{\text { f.s. }} & \text { f.a. } \\
\cline { 2 - 7 } & 1 \underline{a} & 2 \underline{a} & 3 \underline{a} & 4 \underline{a} & & \\
\hline 18-29 & 11,7 & 16,3 & 42,8 & 4,7 & & 19,1 & 19,1
\end{array} \\
& \begin{array}{llllllll}
28 & 25 & 27,6 & 33,5 & 26,1 & 27,4 & 28,3 & 47,4
\end{array} \\
& \begin{array}{ll|l|l|lll}
25-30 & 21,2 & 19,7 & 8,7 & 9,4 & 18,4 & 65,8
\end{array} \\
& \begin{array}{l|l|l|l|lll}
30-35- & 14,3 & 18,9 & 11,6 & 11,8 & 13,1 & 78,9
\end{array} \\
& \begin{array}{ll|l|l|ll|l}
35-48 & 18,5 & 9,2 & 4,3 & 5,9 & 9,1 & 88,8
\end{array} \\
& \begin{array}{ll|l|l|lll}
48-45 & 6,2 & 5,4 & 3,6 & 2,4 & 5,5 & 93,5
\end{array} \\
& 45-50 \quad 4,1 \quad 2,1 \quad 2,2-3,1 \% \\
& \begin{array}{ll|l|l|ll}
H=47,88^{*} \quad 58-55 & 1,8 & 0,8 & -2,4 & 1,4 & 98,8
\end{array} \\
& 55-68 \quad 1,1 \quad 1,3-0,998,9 \\
& 60-65 \quad 0,6 \quad 0,4-0,499,3 \\
& 65-78 \quad 8,2-8,199,4 \\
& 78-75-2-09,4 \\
& 75-80 \quad 0,2-0,199,5 \\
& 89-85--\quad--\quad-99,5
\end{aligned}
$$

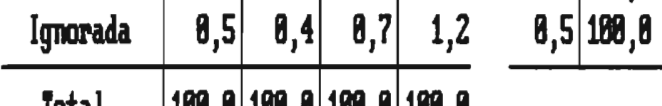

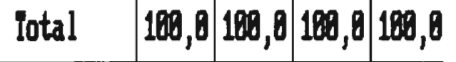

$$
\begin{aligned}
& \text { f.s. = frequitencia relativa } \\
& f . a .=\text { rrequiência relativa acumulada } \\
& H=1,43
\end{aligned}
$$


Tabela 07 : Reincidências, segundo o título do Código Penal transgredido.

\begin{tabular}{|c|c|c|c|c|}
\hline \multirow{2}{*}{ lítulo } & \multicolumn{4}{|c|}{ Reincidências (no) } \\
\hline & $1 \mathrm{a}$ & $2 a$ & $3 a$ & $4 a$ \\
\hline Contra a pessoa.......... & 228 & 68 & 38 & 18 \\
\hline Contra o patrimônio..... & 242 & 74 & 45 & 26 \\
\hline Qutros títulos.......... & 68 & 24 & 11 & 8 \\
\hline Ignarado.................. & 126 & 73 & 44 & 33 \\
\hline Iotal & 656 & 239 & 138 & 85 \\
\hline
\end{tabular}

Tabela 08 : Percentagens de reincidências, segundo o título do Código Penal transgredido.

\begin{tabular}{|c|c|c|c|c|c|c|}
\hline & \multirow{2}{*}{ lítulo } & \multicolumn{4}{|c|}{ Reincidências (\%) } & \multirow{2}{*}{$\bar{x}$} \\
\hline & & $1^{\underline{a}}$ & $2^{\mathrm{a}}$ & $3 \underline{a}$ & $4^{a}$ & \\
\hline \multirow{4}{*}{$H=9,84^{*}$} & Contra a pessoa.......... & 43,8 & 41,8 & 48,4 & 34,6 & 31,5 \\
\hline & Contra o patrimonio..... & 45,6 & 44,6 & 47,9 & 58,8 & 34,6 \\
\hline & Gutros títulos........... & 11,3 & 14,5 & 11,7 & 15,4 & 9,2 \\
\hline & lotal & 100,0 & 100,8 & 180,8 & 160,8 & \\
\hline
\end{tabular}


Tabela 09 : Reincidências, segundo a cor da pele dos criminosos e o intervalo entre as mesmas, em meses.

\begin{tabular}{|c|c|c|c|c|c|c|c|}
\hline Rein. & Intervalo & $\mathrm{BR}$ & Al & PR & $\mathrm{PA}$ & Total & Ignos. \\
\hline \multirow[t]{2}{*}{$1 \mathrm{a}$} & $\begin{array}{lll}8 & -1 \\
1 & -2 \\
2 & -3 \\
3 & -4 \\
4 & -5 \\
\text { Ignor. }\end{array}$ & $\begin{array}{r}485 \\
2 \\
- \\
- \\
- \\
-\end{array}$ & $\begin{array}{l}\frac{10}{-} \\
- \\
- \\
-\end{array}$ & $\begin{array}{l}86 \\
- \\
- \\
- \\
-\end{array}$ & $\begin{array}{l}151 \\
- \\
- \\
- \\
-\end{array}$ & $\begin{array}{r}652 \\
2 \\
- \\
- \\
- \\
-\end{array}$ & \\
\hline & Iotal & 487 & 10 & 86 & 151 & 654 & 2 \\
\hline \multirow[t]{2}{*}{$2 \mathrm{a}$} & $\begin{array}{lll}8 & -1 \\
1 & -2 \\
2 & -3 \\
3 & -4 \\
4 & -5 \\
\text { Ignor. }\end{array}$ & $\begin{array}{r}52 \\
24 \\
12 \\
7 \\
5 \\
24\end{array}$ & $\begin{array}{l}1 \\
- \\
- \\
-\end{array}$ & $\begin{array}{r}12 \\
9 \\
5 \\
2 \\
3 \\
14\end{array}$ & $\begin{array}{r}25 \\
15 \\
10 \\
4 \\
5 \\
9\end{array}$ & $\begin{array}{l}98 \\
48 \\
27 \\
13 \\
13 \\
47\end{array}$ & \\
\hline & Iotal & 124 & 1 & 45 & 68 & 238 & 1 \\
\hline \multirow[t]{2}{*}{$3 \underline{a}$} & $\begin{array}{lll}0 & -1 \\
1 & -2 \\
2 & -3 \\
3 & -4 \\
4 & -5 \\
\text { Ignos. }\end{array}$ & $\begin{array}{r}2 \\
11 \\
7 \\
4 \\
7 \\
13\end{array}$ & $\begin{array}{l}1 \\
- \\
- \\
-\end{array}$ & $\begin{array}{r}? \\
5 \\
2 \\
3 \\
1 \\
10\end{array}$ & $\begin{array}{c}12 \\
11 \\
6 \\
6 \\
1 \\
8\end{array}$ & $\begin{array}{r}42 \\
27 \\
15 \\
13 \\
9 \\
31\end{array}$ & \\
\hline & Total & 64 & 1 & 28 & 44 & 137 & 1 \\
\hline \multirow[t]{2}{*}{$4 \underline{a}$} & 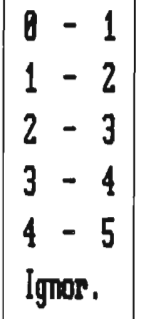 & $\begin{array}{c}9 \\
6 \\
3 \\
6 \\
3 \\
10\end{array}$ & $\begin{array}{l}- \\
- \\
- \\
- \\
-\end{array}$ & $\begin{array}{r}4 \\
3 \\
2 \\
- \\
1 \\
5\end{array}$ & $\begin{array}{l}8 \\
8 \\
6 \\
4 \\
1 \\
8\end{array}$ & \begin{tabular}{r|}
18 \\
17 \\
11 \\
18 \\
5 \\
23
\end{tabular} & \\
\hline & Iotal & 37 & $\cdots$ & 15 & 32 & 84 & 1 \\
\hline
\end{tabular}


Tabela 10 : Médias dos intervalos entre as reincidências, segundo a cor da pele dos criminosos, em anos.

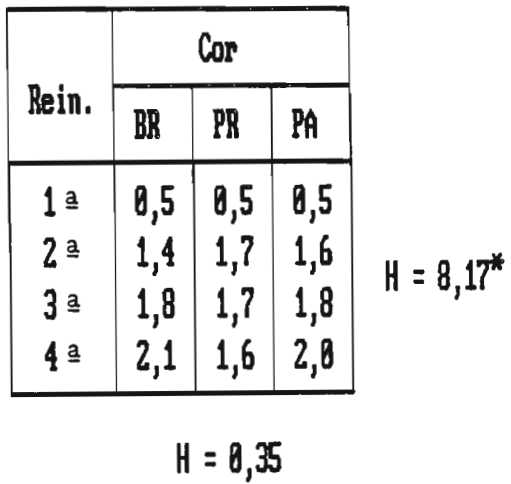

Tabela 11 : Médias aritméticas dos intervalos entre as reincidências criminais, em anos.

\begin{tabular}{|c|c|c|c|c|}
\hline Rein. & $\bar{x}$ & $s$ & is & U1 \\
\hline 1 a & 0,5 & 0,80 & 0,5 & 0,5 \\
2 a & 1,6 & 0,12 & 1,4 & 1,8 \\
3 a & 1,8 & 8,86 & 1,7 & 1,9 \\
4 a & 1,9 & 8,22 & 1,5 & 2,3 \\
\hline
\end{tabular}

$s=$ desuio padräo

IS = linite superior

LI = linite inferior 
Tabela 12 : Reincidências, segundo a idade dos criminosos no momento de cometê-las e intervalo entre as mesmas, em meses.

\begin{tabular}{|c|c|c|c|c|c|c|c|c|c|c|c|c|}
\hline Rein. & Intervalo & $18-20$ & $20-25$ & $25-38$ & $38-35$ & $35-40$ & $48-45$ & $45-50$ & $58-55$ & $55-60$ & 768 & Ignor. \\
\hline \multirow{7}{*}{$1 \underline{a}$} & $0-1$ & 76 & 181 & 139 & 94 & 69 & 41 & 27 & 12 & $?$ & 5 & \multirow[b]{7}{*}{3} \\
\hline & $1-2$ & 1 & - & - & - & - & - & 一 & - & - & 1 & \\
\hline & $2-3$ & - & - & - & - & - & - & - & - & - & - & \\
\hline & $3-4$ & - & - & - & 一 & - & - & - & - & 一 & - & \\
\hline & $4-5$ & - & - & - & - & - & - & - & - & - & - & \\
\hline & Igros. & - & - & - & - & - & - & - & - & - & - & \\
\hline & Iotal & 77 & 181 & 139 & 94 & 69 & 41 & 27 & 12 & 7 & 6 & \\
\hline \multirow{7}{*}{$2 \mathrm{a}$} & $0-1$ & 13 & 19 & 19 & 18 & 11 & 4 & 4 & 2 & 1 & - & \multirow[b]{7}{*}{$t$} \\
\hline & $1-2$ & 8 & 28 & 5 & 6 & 3 & 4 & - & - & 1 & 1 & \\
\hline & $2-3$ & 6 & 10 & $?$ & 2 & 1 & - & - & - & 1 & - & \\
\hline & $3-4$ & 1 & 9 & 2 & 2 & 2 & 1 & - & - & - & - & \\
\hline & $4-5$ & 2 & 4 & 3 & 3 & 1 & - & - & - & - & - & \\
\hline & Ignos. & 8 & 18 & 11 & 3 & 14 & 4 & 1 & - & - & - & \\
\hline & Total & 39 & 80 & 47 & 26 & 22 & 13 & 5 & 2 & 3 & 1 & \\
\hline \multirow{7}{*}{$3 a$} & $0-1$ & 14 & 7 & 4 & 7 & 3 & 3 & - & 1 & 一 & - & \multirow[b]{7}{*}{1} \\
\hline & $1-2$ & 11 & 8 & 3 & 2 & 1 & 2 & - & - & - & - & \\
\hline & $2-3$ & 6 & 4 & 1 & 2 & 1 & - & - & 1 & - & - & \\
\hline & $3-4$ & 8 & 3 & - & 1 & 1 & - & - & - & - & - & \\
\hline & $4-5$ & 4 & 3 & 1 & 1 & - & - & - & - & - & - & \\
\hline & Ignos. & 16 & 11 & 3 & 3 & - & - & - & 1 & 一 & 一 & \\
\hline & Iotal & 59 & 36 & 12 & 16 & 6 & 5 & -- & 3 & -- & -- & \\
\hline \multirow{7}{*}{$4 \underline{a}$} & $8-1$ & 6 & 3 & 3 & 2 & 1 & 1 & - & - & - & - & \multirow[b]{7}{*}{1} \\
\hline & $1-i$ & 8 & 6 & - & 2 & 1 & - & - & - & 一 & - & \\
\hline & $2-3$ & 5 & 1 & - & 3 & 2 & - & - & - & - & - & \\
\hline & 3 & 3 & 2 & 2 & 一 & 1 & 1 & - & 1 & - & - & \\
\hline & 4 & 3 & 2 & - & - & - & - & - & - & 一 & - & \\
\hline & Ignos. & 13 & 5 & 3 & 3 & - & - & - & 1 & - & - & \\
\hline & Iotal & 38 & 19 & 8 & 18 & 5 & 2 & -- & 2 & --- & --- & \\
\hline
\end{tabular}


Tabela 13 : Reincidências, segundo a idade dos criminosos no momento de cometê-las e intervalo entre as mesmas, em anos.

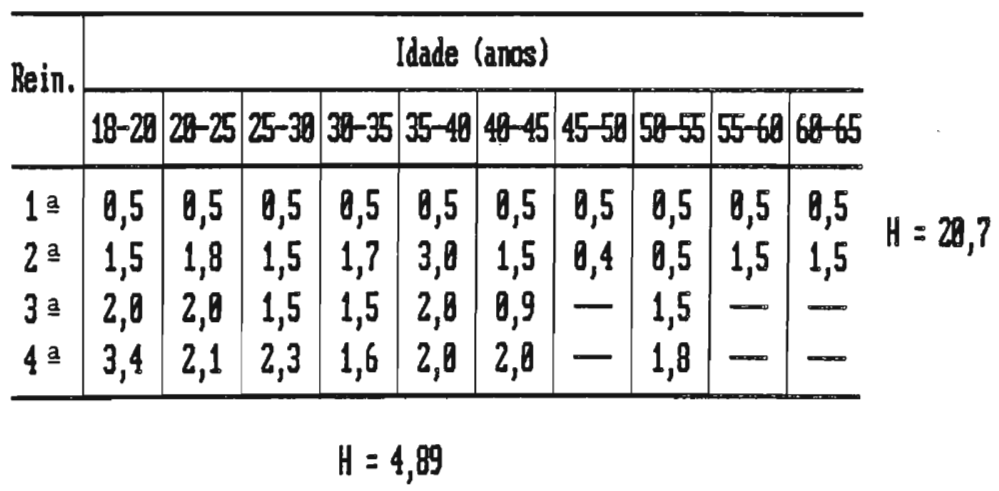


Tabela 14 : Reincidências, segundo o título do Código Penal transgredido e intervalo entre as mesmas, em meses.

\begin{tabular}{|c|c|c|c|c|c|c|}
\hline \multirow{2}{*}{ Rein. } & \multirow{2}{*}{ Intervalo } & \multicolumn{3}{|c|}{ Iítulo Código Penal } & \multirow{2}{*}{ Iotal } & \multirow{2}{*}{ Ignor. } \\
\hline & & $I$ & II & Outro & & \\
\hline \multirow{7}{*}{$1^{\underline{a}}$} & $0-1$ & 259 & 271 & 98 & 628 & \multirow[b]{7}{*}{25} \\
\hline & $1-2$ & 3 & 一 & - & 3 & \\
\hline & $2-3$ & - & 一 & - & 一 & \\
\hline & $3-4$ & - & 一 & - & - & \\
\hline & $4-5$ & - & 一 & - & - & \\
\hline & Ignor. & 一 & 一 & - & 一 & \\
\hline & Iotal & 262 & 271 & 98 & 631 & \\
\hline \multirow{7}{*}{$2 \mathrm{a}$} & $0-1$ & 39 & 29 & 13 & 81 & \multirow[b]{7}{*}{28} \\
\hline & $1-2$ & 17 & 23 & 5 & 45 & \\
\hline & $2-3$ & 10 & 12 & 5 & 27 & \\
\hline & $3-4$ & 1 & $?$ & 2 & 10 & \\
\hline & $4-5$ & 6 & 3 & 2 & 11 & \\
\hline & Ignor. & 19 & 19 & 7 & 45 & \\
\hline & Total & 92 & 93 & 34 & 219 & \\
\hline \multirow{7}{*}{$3 a$} & $0-1$ & 13 & 17 & 4 & 34 & \multirow[b]{7}{*}{16} \\
\hline & $1-2$ & 6 & 11 & 6 & 23 & \\
\hline & $2-3$ & 9 & $?$ & 2 & 18 & \\
\hline & $3-4$ & 6 & 6 & 1 & 18 & \\
\hline & $4-5$ & 4 & 4 & - & 8 & \\
\hline & Ignor. & 13 & 12 & 1 & 26 & \\
\hline & Iotal & 51 & 57 & 14 & 122 & \\
\hline \multirow{7}{*}{$4 \stackrel{a}{a}$} & $\theta-1$ & 5 & 6 & 3 & 14 & \multirow[b]{7}{*}{11} \\
\hline & $1-2$ & 5 & 9 & 2 & 16 & \\
\hline & $2-3$ & 4 & 3 & 3 & 10 & \\
\hline & $3-4$ & 3 & 6 & - & 9 & \\
\hline & $4-5$ & 2 & 3 & - & 5 & \\
\hline & Ignor. & 9 & 10 & 1 & 28 & \\
\hline & Iotal & 28 & 37 & 9 & 74 & \\
\hline
\end{tabular}


Tabela 15 : Médias aritméticas dos intervalos entre as reincidências, segundo o título do Código Penal transgredido, em anos.

\begin{tabular}{c|c|c|c}
\hline \multirow{2}{*}{ Reinc. } & \multicolumn{3}{|c}{ rítulo Código Penal } \\
\cline { 2 - 4 } & $I$ & II & Outro \\
\hline $1 a$ & 0,5 & 0,5 & 0,5 \\
$2 a$ & 1,4 & 1,6 & 1,6 \\
$3 a$ & 2,0 & 1,8 & 1,6 \\
$4 a$ & 2,1 & 2,2 & 1,5 \\
\hline \multicolumn{4}{c}{$H=0,81^{*}$}
\end{tabular}$\quad H=8,89^{*}$


Fig. 01 : Reincidências, segundo a cor da pele dos criminosos.

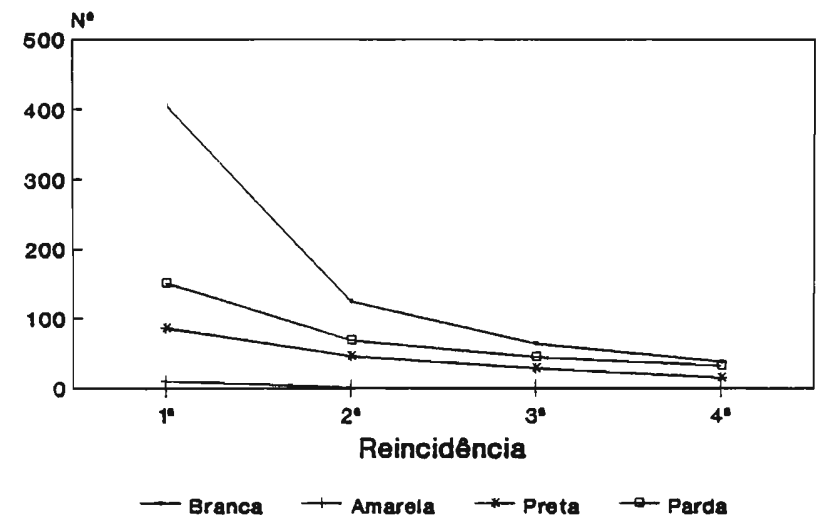

Fig. 02 : Percentagens de reincidência, segundo a cor da pele dos criminosos.

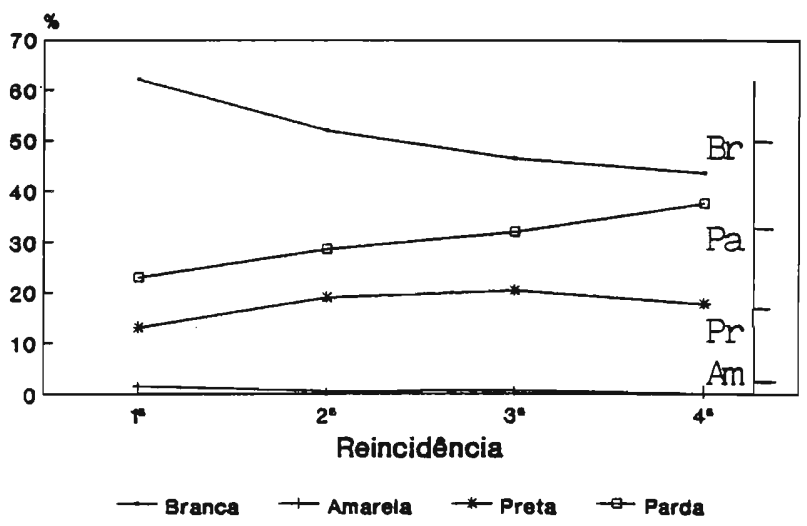


Fig. 03 : Coeficientes de reincidência criminal, para cada 100.000 pessoas da mesma cor.

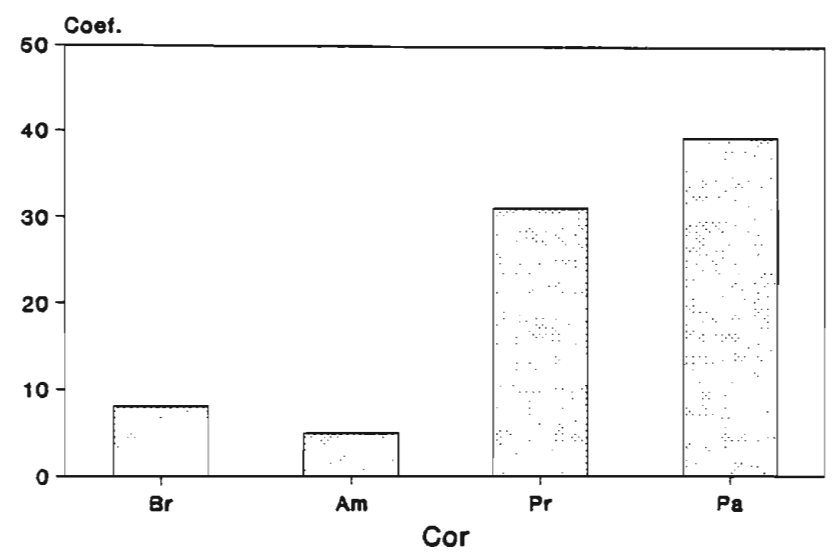

Fig. 04 : Reincidências, segundo a idade dos criminosos ao cometê-las.

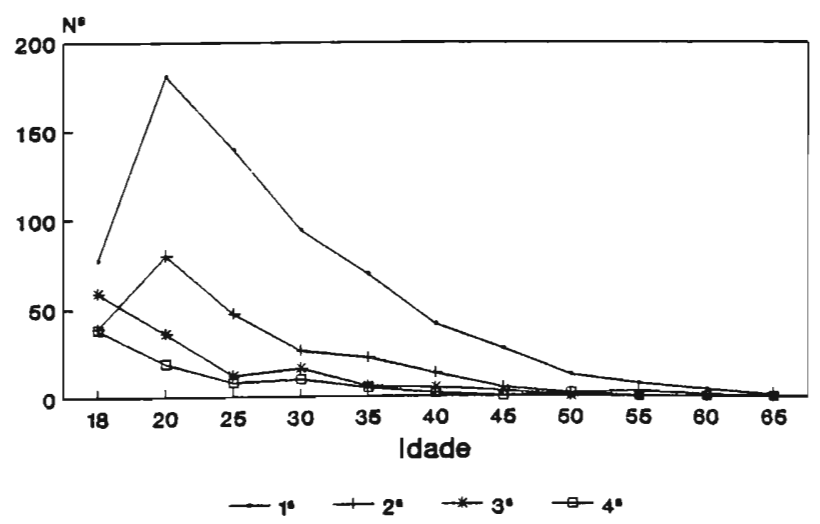


Fig. 06 : Reincidências, segundo o título do Código Penal transgredido.

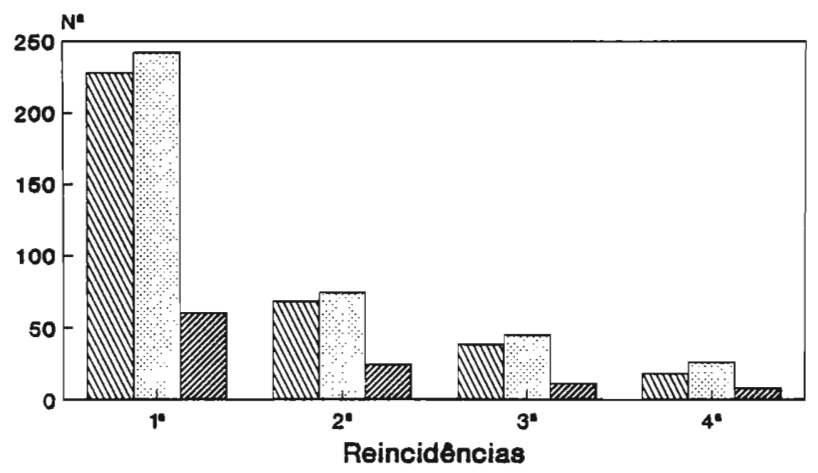

SIIIV I II WIIA Out. Titulos

Fig. 07 : Percentagens de reincidências, segundo o título do Código Penal transgredido.

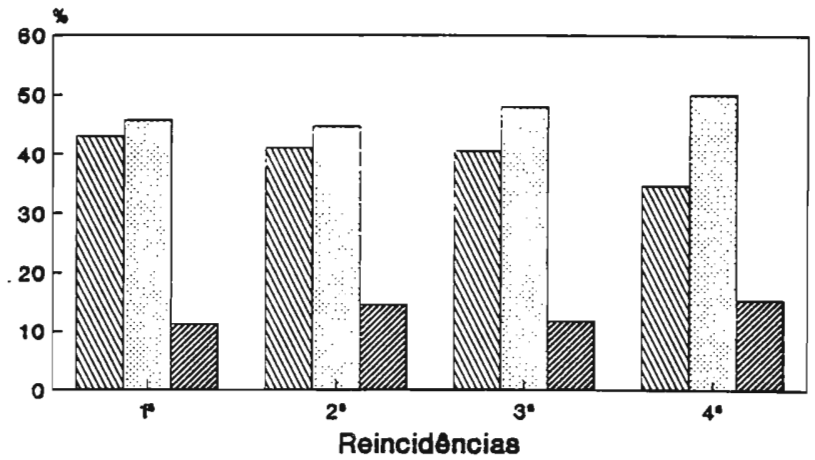

\$IVI । $\square$ II WIA Out. TItulos 
Fig. 08 : Médias dos intervalos entre as reincidências, segundo a cor da pele dos criminosos.

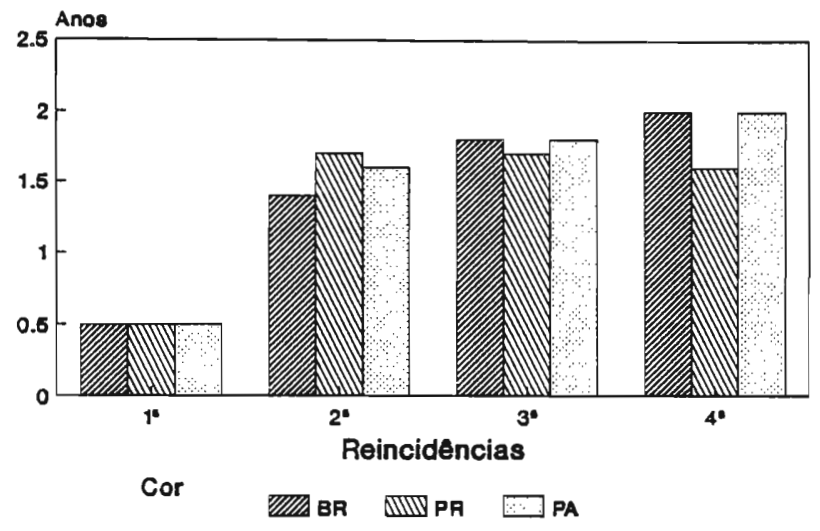

Fig. 09 : Médias aritméticas dos intervalos entre as reincidências criminais e seus limites de confiança 95\%.

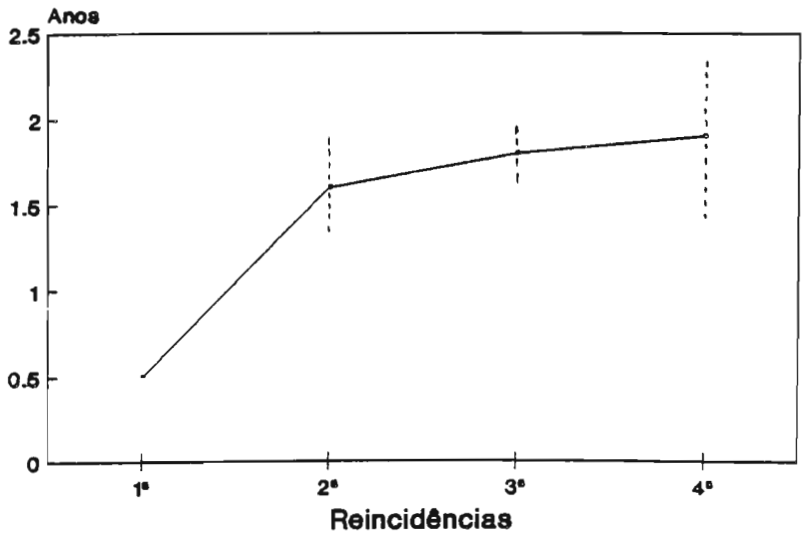


Fig. 11 : Médias aritméticas dos intervalos entre as reincidências, segundo o título do Código Penal transgredido.

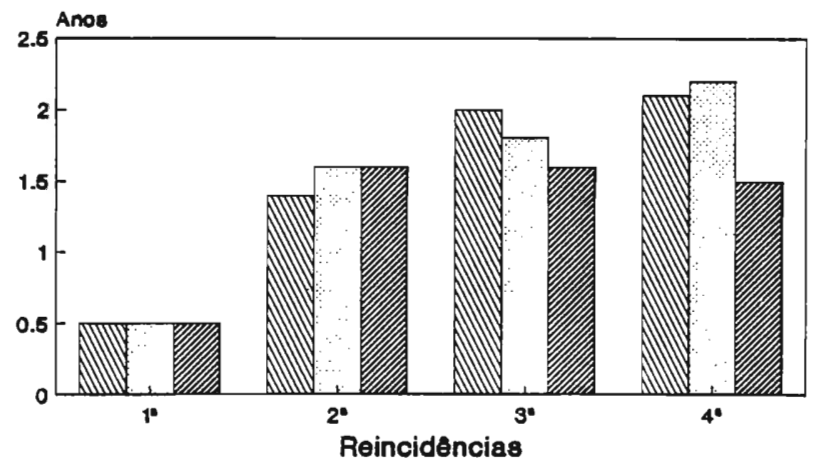

बIIII। $\square$ IIIS Out. Tituloe 


\section{Bibliografia}

1 - GOPPINGER, H. Criminologia. Madrid : Reus, 1967.

2 - LOPEZ-REY, M. Criminologia. Buenos Aires : Aguilar, 1971.

3 - RODELLO, C. de C.; BORDINI, E. B. T.; ABREU, S. F. A. Estimativa de reincidência criminal. Temas IMESC : sociedade, direito, saúde. São Paulo, v.1, n.1, p.61, 1984.

4 - SÁ, A. A. - Reincidência criminal. São Paulo : EDUSP, 1987. p.11.

5 - CARVALHO, H. V. de. Manual de Introdução ao Estudo da Criminologia. São Paulo : Esc. Polícia de São Paulo, 1961. p.236.

São Paulo, 21 de maio de 1990 